\title{
Analysis of Anomalous Tropical Cyclone Activities over the Western North Pacific and the South China Sea in 2015
}

\author{
Dandan Yu Lishan Li Lei Wan
}

2433 Mailbox, Beijing 100081, China

\section{5 年西北太平洋和南海热带气旋活动特征及 成因分析}

余丹丹 李荔珊 万雷

北京市 2433 信箱, 北京, 100081, 中国

\begin{abstract}
Abstraçt
Tropical cyclone (TC) activities over the western North Pacific and the South China Sea in 2015 have such characteristics as so many typhoons in winter and spring, so few typhoons in the South China Sea, generated source is easier than usual. Based on NCEP/NCAR reanalysis data, and the Outgoing Long wave Radiation (OLR) data from NOAA, some primary researches are performed. The results show that the abnormal warmer SST in the western North Pacific and the South China Sea is the key factors in TC abnormal activities; and external forcing of sea surface temperature anomalies caused by Walker circulation ascending area is located in the central and eastern equatorial Pacific, the vast west Pacific is a descending area, the Pacific subtropical high strengthens and spreads westward, East Asian summer monsoon is weak, ITCZ location is southerly, abnormal heat is easterly, which leads to the TCs generated source is easier than usual and TC number in the South China Sea is less than normal.
\end{abstract}

Keywords: synoptic meteorology; tropical cyclones; non-uniform heating; the subtropical high;
摘要

利用 NCEP / NCAR 再分析资料和美国 NOAA 向外长波辐射 (OLR) 等资料, 对 2015 年西北太 平洋和南海热带气旋活动具有冬春台风数量 多、南海台风数量少、生成源地偏东等主要特 点及其成因进行了初步分析。结果表明: 赤道 中东太平洋海温异常偏暖是导致热带气旋活 动异常的重要原因, 海温外强迫异常造成沃克 环流上升区位于赤道中东太平洋, 广阔的西太 平洋为下沉区, 西太平洋副热带高压偏强, 位 置偏西, 东亚夏季风偏弱, 热带辐合带偏南, 异常热源偏东, 导致热带气旋生成源地位置偏 东, 南海热带气旋生成个数偏少。

关键字: 天气学; 热带气旋; 非绝热加热; 副热带高压

\section{1. 引言}

西北太平洋是全球热带气旋发生频数最 多、分布范围最广的海域。我国濒临西北太平 洋, 每年热带气旋灾害造成的损失高居其他自 然灾害之首。随着全球变暖的持续发展, 全球 高影响热带气旋事件的频发, 热带气旋灾害造 成的损失日趋严重, 影响范围呈现扩大化的态 势, 由沿海地区向内陆深入 ${ }^{[1]}$ 。1504 号超强台 风 “美莎克” 是北半球有气象记录以来, 3 月 生成的最强热带气旋, 是继 2008 年台风 “浣 
熊”之后, 7 年来首个在 4 月进入南海北部的 热带气旋。1522 号超强台风 “彩虹” 为 1949 年以来 10 月登陆广东最强热带气旋, 登陆时 中心附近最大风力有 15 级 $(50 \mathrm{~m} / \mathrm{s})$ 。

ENSO 事件与西北太平洋热带气旋发生频 数关系密切。赤道东太平洋海温异常可以通过 影响太平洋低纬地区的纬圈环流、热带辐合带、 海温等、对流, 风切变幅度进而影响西太平洋 台风的活动频次, 强度, 位置 ${ }^{[2-5]}$ 。西北太平 洋副热带高压（以下，简称副高）的位置和强 度等特征的演变对热带气旋的生成、发展和移 动都有重要影响 ${ }^{[6-8]}$, 同时, 它也是预测热带 气旋频数的一个重要的气候因子 ${ }^{[9]}$ 。2015 年爆 发了一次极强厄尔尼诺事件, 全球诸多异常天 气事实都与赤道中东太平洋海温持续偏暖有 关, 2015 年副高异常偏强、偏南、偏西, 南 海热带气旋异常偏少, 这无疑也与该年太平洋 海温的反常行为密切相关。

基于此, 本文采用上海台风所提供的 1949 2015 年西北太平洋编号热带气旋资料, 源于美国国家环境预报中心 NCEP（Nationa1 Centers for Environmental Prediction) 和 国家大气研究中心 NCAR (National Centers for Atmospheric Research) 的同期的逐日再 分析资料 (风场、高度场、温度场、湿度场和 垂直速度场）以及美国国家海洋和大气管理局 NOAA(National Oceanic and Atmospheric Administration) 卫星观测的 OLR 资料 (2. $5^{\circ}$ $\times 2.5^{\circ}$ 网格)。对 2015 年西北太平洋和南海 热带气旋活动特点进行了回顾, 揭示 ENSO 事 件期间东亚夏季风活动异常与西北太平洋热 带气旋活动异常的关系, 建立东亚夏季风系统 成员对热带气旋影响的天气学图像, 为热带气 旋活动的长期气候预测提供有益的参考。

\section{2015 年热带气旋活动概况}

（1）起编时间偏早，冬春台风偏多

2015 年第 1 号台风 “米克拉” 于 1 月 14 日生成, 比常年 (3 月 20 日) 明显偏早。 2015 年是自 1971 年以来冬春台风最活跃的一 年, $1 \sim 5$ 月西北太平洋 (含南海) 共有 7 个 热带气旋生成, 较常年 (2.9 个) 异常偏多, 尤其是 2015 年春季 (3 月 5 月), 热带气旋 生成个数明显偏多, 强度偏强, 历史罕见, 春
季生成的 5 个热带气旋中有 3 个达到超强台风 级, 其中 1504 号超强台风 “美莎克” 是北半 球有气象记录以来, 3 月生成的最强热带气旋, 它以偏西路径长驱直入南海, 是继 2008 年台 风 “浣熊”之后, 7 年来首个在 4 月进入南海 北部的热带气旋。

表 12015 年西北太平洋 (含南海) 热带气旋 各月生成个数（平均值: 1949-2014 年)

\begin{tabular}{ccccccccccccc}
\hline \hline 月份 & $\begin{array}{l}1 \\
\text { 月 }\end{array}$ & $\begin{array}{c}2 \\
\text { 月 }\end{array}$ & $\begin{array}{c}3 \\
\text { 月 }\end{array}$ & $\begin{array}{c}4 \\
\text { 月 }\end{array}$ & $\begin{array}{c}5 \\
\text { 月 }\end{array}$ & $\begin{array}{c}6 \\
\text { 月 }\end{array}$ & $\begin{array}{c}7 \\
\text { 月 }\end{array}$ & $\begin{array}{c}8 \\
\text { 月 }\end{array}$ & $\begin{array}{c}9 \\
\text { 月 }\end{array}$ & $\begin{array}{c}10 \\
\text { 月 }\end{array}$ & $\begin{array}{c}11 \\
\text { 月 }\end{array}$ & $\begin{array}{c}12 \\
\text { 月 }\end{array}$ \\
\hline $\begin{array}{c}\text { 2015 } \\
\text { 年 } \\
\text { 平均 } \\
\text { 值 }\end{array}$ & 1 & 1 & 2 & 1 & 2 & 2 & 4 & 3 & 5 & 4 & 1 & 1 \\
\hline \hline
\end{tabular}

（2）源地偏东, 强度偏强

2015 年热带气旋生成源地位置偏东, 平 均经度 $149.7^{\circ} \mathrm{E}$, 有 7 个热带气旋生成于 $160^{\circ}$ $\mathrm{E}$ 以东海域, 有 3 个热带气旋生成于 $170^{\circ} \mathrm{E}$ 以东海域。由于热带气旋生成源地偏东, 西行 距离较长, 宽阔暖洋面为台风发展提供有利条 件, 因此, 2015 年热带气旋强度偏强, 台风 级别(含) 以上的热带气旋个数占总个数 $77.8 \%$, 有超过一半的热带气旋达到超强台风级 (14 个), 超强台风的数量是常年的 2 倍。

（3）南海台风偏少，影响偏弱

2015 年影响南海海域热带气旋有 7 个, 较常年平均偏少 (10 个), 影响范围强度偏弱。 1522 号强台风 “彩虹” 以西北路径横穿南海, 并以强台风级在广东省湛江沿海登陆, 为本年 度对华南沿海造成影响最严重的南海台风。除 此以外, 其它 5 个南海热带气旋影响强度范围 均偏弱。

（4）西行台风偏多，北上台风偏少

2015 年西太平洋 (含南海) 生成的 27 个 热带气旋中, 以偏西路径影响我国的热带气旋 有 10 个，占总个数 $37.0 \%$; 近海北上影响我 国的热带气旋有 3 个，占总个数 $11.1 \%$ 。

（5）７月台风集中频发

2015 年 7 月, 1509 号超强台风 “灿鸿”、 1510 号台风“莲花”、1511 号超强台风“浪卡” 接踵而至, 同时在西北太平洋上活动, 形成了 “三旋共舞” 的局面。

总的来说，2015 年热带气旋生成个数基 本接近多年平均值, 但是热带气旋生成位置普 遍偏东，有近一半在 $150^{\circ} \mathrm{E}$ 以东生成，南海 和菲律宾群岛以东台风源地生成的热带气旋 


\section{Risk Analysis and Crisis Response in Big Data Era (RAC-16)}

相对偏少; 冬春台风偏多, 1 5 月生成热带 气旋个数均高于多年平均值, 夏秋台风略偏少, 8 月热带气旋个数较常年同期偏少 2 个。那么 造成热带气旋活动异常的原因是什么?

\section{3. 热带气旋生成频数异常的成因分析}

3. 1 厄尔尼诺事件的影响

2014 年 5 月赤道太平洋发生的厄尔尼诺 事件，截止到 2016 年 4 月，已经持续了 23 个 月, 峰值出现在 2015 年 11 月。此次厄尔尼诺 事件持续时间、累计强度 $\left(29.7^{\circ} \mathrm{C}\right)$ 和峰值 强度 $\left(2.9^{\circ} \mathrm{C}\right)$ 都达到了历史最高, 已成为 20 世纪以来最强的厄尔尼诺事件, 也是自 1951 年以来持续时间最长的厄尔尼诺事件。 虽然目前本次超强厄尔尼诺事件已进入快速 衰减过程, 但其后续影响仍将持续。

从 2015 年赤道太平洋地区各季海温距平 分布（图 1 略）可以看出：从前冬到秋季, 赤 道中东太平洋大部分地区海温为正距平分布, 暖海温中心范围和强度不断扩大, 表明厄尔尼 诺事件持续发展, 前冬, 赤道太平洋中部海温 升温明显, 春季, 暖海温范围扩大到赤道东太 平洋, 暖海温中心位于日界线附近, 中心强度 超过 $1.5^{\circ} \mathrm{C}$, 秋季, 暖海温中心东扩到 $110^{\circ}$ $\mathrm{W}$ 附近，中心强度超过 $3^{\circ} \mathrm{C}$ 。由于赤道西太平 洋附近 $\left(120^{\circ} \mathrm{E}-140^{\circ} \mathrm{E}\right)$ 海域海温持续偏低, 对流活动受到抑制, 导致该海域生成的热带气 旋明显偏少, 相反, 冬春季, 赤道太平洋中部 $\left(150^{\circ} \mathrm{E}\right)$ 异常海温暖中心有利于热带气旋在 该海域生成和发展, 这也是 2015 年冬春热带 气旋生成个数偏多, 生成源地偏东的最主要原 因。值得注意的是, 前冬和春季, 南海-菲律 宾以东海域海温整体偏低, 无法为热带气旋提 供足够的能量, 不但导致该海域生成的热带气 旋偏少，而且使得经过该海域的热带气旋途中 减弱消散 (如 1504 号超强台风 “美莎克”), 夏秋季, 该海域海温逐渐升高, 正距平范围不 断扩大, 导致夏秋季影响我国的热带气旋多而 集中。由此可见, 赤道太平洋海温异常特征与 2015 年热带气旋的活动特点密切相关, 赤道 太平洋中部的异常暖水状态对热带气旋的发 生和加强尤为有利, 该地区海温持续偏高, 导 致热带气旋生成位置异常偏东。

从纬圈环流来看, 2015 年 “东暖西冷”
的厄尔尼诺年海温分布, 直接导致沃克环流发 生异常 (图 2 略), 从前冬到秋季, 沃克环流 的主要上升区从西太平洋东移到日界线附近, 尤其是到了夏秋季, 广阔的西太平洋 $\left(120^{\circ} \mathrm{E}\right.$ $-160^{\circ}$ E) 皆为下沉区, 沃克环流异常上升支 位于 $160^{\circ} \mathrm{E}$ 以西海域, 这里海温偏高, 对流 旺盛, 从而造就了 2015 年台风源地异常偏东 的事实。

\section{2 东亚夏季风系统活动异常的影响}

南海夏季风强度指数的逐候演变显示 (图 $3 \mathrm{a}$ ， 2015 年南海夏季风 5 月 5 候爆发，爆发 时间与常年基本一致, 除 6 月下旬到 7 月中旬, 南海夏季风出现阶段性偏强外, 其余时段强度 总体较常年同期异常偏弱。根据文献 (陶诗言 等, 2001) 关于东亚季风指数定义, 计算 1979 2015 年间, $\left(10^{\circ} \mathrm{N}-20^{\circ} \mathrm{N}, 100^{\circ} \mathrm{E}-150^{\circ} \mathrm{E}\right)$ 区域的 $6 \sim 8$ 月平均 $850 \mathrm{hPa}$ 的 $\mathrm{U}$ 分量减去 $\left(25^{\circ}\right.$ $\mathrm{N}-35^{\circ} \mathrm{N}, 100^{\circ} \mathrm{E}-150^{\circ} \mathrm{E}$ ) 区域的 $6 \sim 8$ 月平 均 $850 \mathrm{hPa}$ 的 $\mathrm{U}$ 分量 (图 $3 \mathrm{~b}$ ), 发现 2015 年 基本属于夏季风正常年。再以 $4 \sim 10$ 月 $850 \mathrm{hPa}$ 纬向风沿 $100^{\circ} \mathrm{E} \sim 150^{\circ} \mathrm{E}$ 平均的纬度-时间 剖面 (图 4), 来看东亚夏季风的强弱变化。 总的来说, 4 10 月赤道西风偏强, 这与本年 度发生厄尔尼诺事件相吻合, 5 月中旬, 伴随 南海夏季风全面爆发, 南海一带东风迅速转为 西风, 副高南撤东退。随后, 季风云涌中断, 南海一带又被副高占据, 6 月中旬, 低纬地区 出现了一次明显的季风北涌, 西风向北扩展至 $20^{\circ} \mathrm{N}$ 附近, 副高也向北挺进, 之后季风一直 偏弱, 副高偏南。

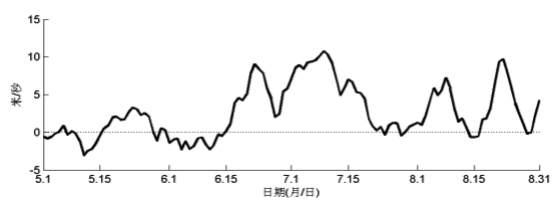

(a)

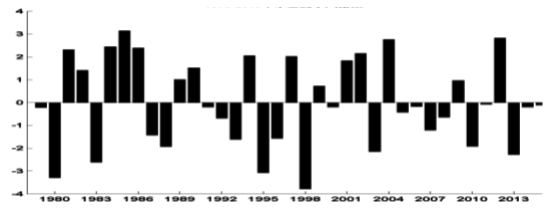

(b)

图 3 (a) 2015 年 5-8 月南海夏季风强度指数 
逐日变化 (b) 1979-2015 年东亚夏季风强度指 数的逐年变化

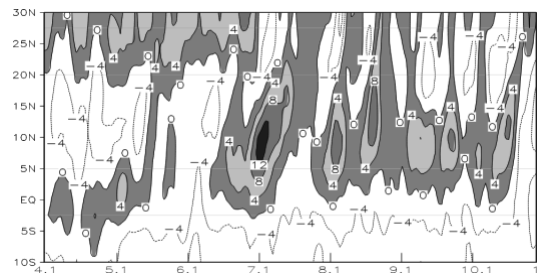

图 4 沿 $100^{\circ} \mathrm{E} \sim 150^{\circ} \mathrm{E}$ 平均的 $850 \mathrm{hPa}$ 纬向 风纬度一时间剖面(单位: $\mathrm{m} \cdot \mathrm{s}^{-1}$ )

\section{3 副热带高压的影响}

2015 年西太平洋副热带高压的主要特点 表现为: 副高强度异常偏强、西伸脊点异常偏 西, 脊线在夏季后期到秋季偏南, 从 2015 年 副高强度、西伸脊点及脊线指数 ${ }^{[10]}$ 逐月演变 (图 5) 可以看出：除了 2 月，几乎全年副高 面积指数都在均值以上, 副高西脊点指数都在 均值以下, $7 \sim 10$ 月, 副高脊线位置异常偏南。 从 2015 年副高脊线指数和东西位置指数的逐 日演变（图 6) 也可以看出: 整体上, 副高脊 线基本没有越过 $30^{\circ} \mathrm{N}$, 副高关键区以负浴度 为主, 位置偏西, 尤其是 8 月, 副高异常南落, 向西扩展。在这种强大的副高体的控制下, 南 海-西太平洋海域 $\left(100^{\circ} \mathrm{E} \sim 140^{\circ} \mathrm{E}, 5^{\circ} \mathrm{N} \sim\right.$ $25^{\circ} \mathrm{N}$ ）都被副高所控制, 以下沉气流为主, 抑制了该地区对流的发展, 不利于热带气旋的 生成, 从而导致南海热带气旋明显减少。8 月 副高脊线的异常南压也是导致该月热带气旋 生成偏少的重要原因, 9 月随着副高北跳, 热 带气旋的活动才开始活跃起来。
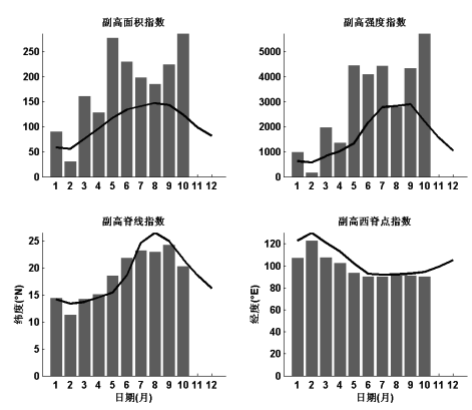

图 52015 年副高面积指数和西脊点指数的 逐月变化（粗实线为多年平均值）

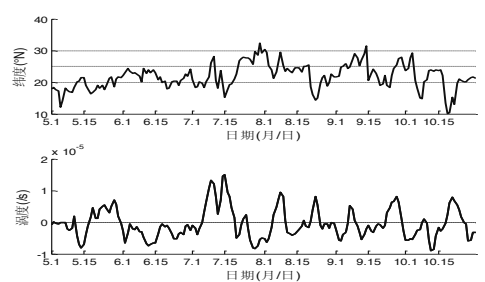

图 62015 年 $5 \sim 10$ 月逐日（a）副高脊线指数 和 (b) 副高东西位置指数的变化曲线

进一步分析可知, 由于赤道中东太平洋海 温异常偏暖, 整个赤道地区平均海温上升, 南 北温度梯度进一步加剧, 促使赤道哈得来环流 发展, 副热带的下沉分支强烈发展, 使得副高 加强。副高的异常强大, 热带辐合带偏弱, 位 置偏南, 热带西太平洋上空的对流活动受到抑 制, 热带气旋生成缺乏必要的初始扰动条件, 故生成个数较常年偏少。为此下面将进一步探 讨热带辐合带对热带气旋活动的影响。

\section{3.1 热带辐合带}

图 7 (图略) 上可以清楚地看到副高和热 带辐合带的强弱和位置关系。从前冬到秋季, 共同特征是副高异常强大, 向西伸展, 西北太 平洋完全在副高的控制下, 南海和菲律宾以东 为 OLR 高值区, 对流不活跃, 这与厄尔尼诺引 起的沃克环流异常下沉支位置相吻合, 而赤道 太平洋中东部为 OLR 低值区, 对应沃克环流异 常上升支, 对流活动频繁。夏季, 赤道西风向 东发展, 它们与副高南侧的东风在赤道太平洋 中部汇合, 使得热带气旋源地偏东, 热带辐合 带偏弱, 位置偏南, 不利于热带气旋生成。

\subsection{2 大气视热源}

绝大多数的热带环流是热力驱动的, 为此 下面将从热源的角度进行讨论。文中大气视热 源 $\mathrm{Q}_{1}$ 的计算方案 ${ }^{[11]}$ 如下:

$$
\mathrm{Q}_{1}=c_{p}\left(\frac{\partial T}{\partial t}+\vec{V} \cdot \nabla T+\omega\left(\frac{p}{p_{0}}\right)^{k} \frac{\partial \theta}{\partial p}\right)
$$

其中 $T$ 为温度, $q$ 为比湿, $\theta$ 为位温, $\omega$ 为 $p$ 坐标的垂直速度, $k=R / C p, R$ 和 $C p$ 分别 为干空气气体常数和定压比热, $L$ 为潜热, $\vec{V}$ 为 水平风矢量。将上式分别垂直积分可得整层的 视热源 $<\mathrm{Q}_{1}>$

$$
<\mathrm{Q}_{1}>=\frac{1}{\mathrm{~g}} \int_{P_{0}}^{p_{\mathrm{s}}}\left(Q_{1}\right) d p
$$


Risk Analysis and Crisis Response in Big Data Era (RAC-16)

式中 P0 指 $1000 \mathrm{hPa}$, PS 指的是 $100 \mathrm{hPa}$ 。图 8 为 2015 年各季平均对流层整层垂直积分的 大气视热源的距平分布。图中, 异常热源偏东, 主要分布在赤道太平洋中东部上, 南海及菲律 宾以东上空皆为干燥和辐射冷却区, 视热源较
常年明显减弱, 热带气旋主要源区的热力条件 不利于热带气旋的生成和发展, 因此造成热带 气旋活动偏少。由于副热带高压及平均脊区大 气辐射冷却并失去水分, 因此图上负距平区的 分布很好地反映了副高异常强大和位置偏西。

(a)

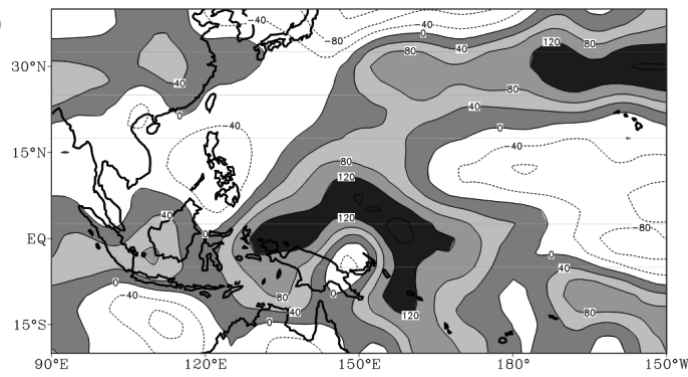

(b)

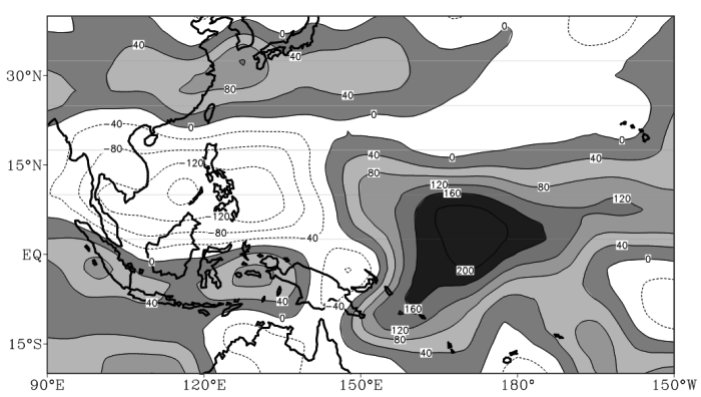

(c)

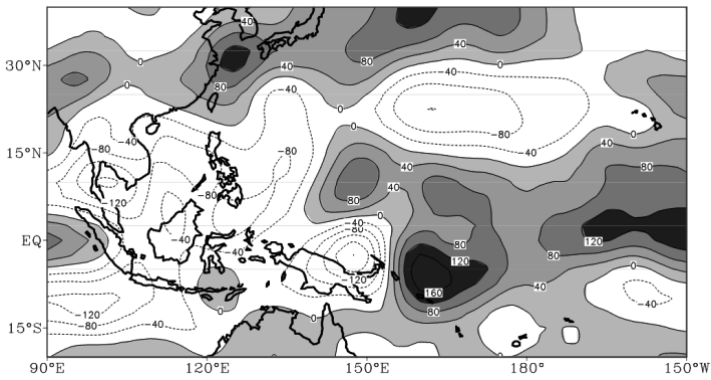

(d)

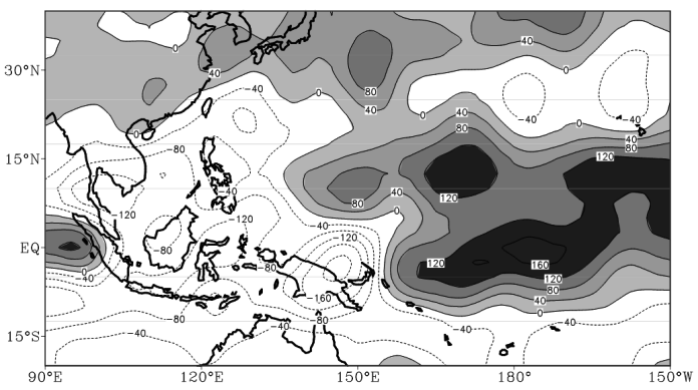

图 8. 2015 年 (a) 前冬 (翌年 $12-2$ 月)、 (b) 春季 (3-5 月)、 (c) 夏季 (6-8 月)、 (d) 秋季 (9-11 月）对流层整层垂直积分的大气视热源 Q1 距平分布 
总的来说伴随着年内的厄尔尼诺事件, 海 温外强迫的异常造成垂直环流异常, 东亚夏季 风活动异常, 从而影响热带气旋活动异常。具 体来讲, 由春入夏, 赤道东太平洋海温异常偏 暖, 沃克环流上升区位于赤道中东太平洋, 广 阔的西太平洋为下沉区, 西太平洋副热带高压 偏强, 位置偏西, 东亚夏季风偏弱, 西南季风 与副高南缘东南风形成的气旋性切变偏弱, 不 利于热带气旋的生成, 热带辐合带偏南, 热带 对流活跃区位于赤道以南, 异常热源偏东, 南 海和菲律宾以东地区对流活动受到抑制, 热带 气旋生成个数偏少。

\section{4. 小结}

（1）2015 年是西北太平洋和南海上热带气 旋主要呈现冬春台风数量多、南海台风数量少、 生成源地偏东等主要特点。

（2）2015 年赤道中太平洋海温异常偏暖可 能是导致冬春台风频数异常偏多、“初台” 来 得早的重要原因。

（3）２015 年热带气旋活动异常与东亚夏季 风活动异常有关, 东亚夏季风偏弱, 副高南压, 热带辐合带偏南, 南海和菲律宾以东地区为沃 克环流下沉区, 对流活动受到抑制, 这是造成 2015 年南海热带气旋偏少的直接原因。

（4）2015 年赤道中东太平洋海温异常偏暖, 南北温度梯度进一步加剧, 促使 Hadley 环流 下沉支强烈发展, 使得副高偏强。副高异常强 大、持续偏西、呈带状分布从而导致热带气旋 多西行影响我国。

\section{参考文献}

[1]雷小途,徐明,任福民.全球变暖对台风活动 影响的研究进展 [J]. 大气科 学,2009,67(5):680-688.

[2] 王会军,范可,孙建奇等. 2007. 关于西太平洋 台风气候变异和预测的若干研究进展.大气
科学, 31(6):1076-1081.

[3] 陶丽, 靳甜甜, 兴海娟.2013. 西北太平洋热带 气旋气候变化的若干研究进展 [J]. 大气科 学学报,36(4):504-512.

[4] 朱伟军, 胡瑞卿, 徐明等.2014. 西北太平洋和 南海不同时段生成热带气旋频数及其水汽 条件的分类 [J]. 大气科学学报, 37(3):344-353.

[5] Camargo S J , Sobel A H. 2005.Western North Pacific tropical cyclone intensity and ENSO[J]. J. Climate,18(15):2996-3006.

[6] 陈联寿. 盛夏亚洲中高纬流型与西太平洋热 带气旋路径的关系 $[J]$.气象学报,1965,35(4): 476-485.

[7] Wang B, Wu R R. Peculiar temporal structure of the South China Sea summer monsoon [J]. Advances in Atmospheric Sciences, 1997,14: 177-194.

[8] 龚振淞, 陈丽娟..2010 年西北太平洋与南 海热带气旋活动异常的成因分析 [J]. 气候 与环境研究, 2013,18(3):342-352.

[9] 范可. 西北太平洋台风生成频次的新预测因 子和新预测模型 [J]. 中国科学 (D 辑), 2007,37 (9): 1260- 1266.

[10] 余丹丹, 张韧等.基于交叉小波与小波相 干的西太平洋副高与东亚夏季风系统的关 联性分析[J].南京气象学报,2007,30(6): 755-769.

[11] Yanai $M$, Esbensen $S$ and Chu $J$ H. Determination of bulk properties of tropical cloud clusters from large-scale heat and moisture budgets [J].J.Atmos.Sci.,1973,30: 611-627. 